\title{
Dissection of the extracranial vertebral artery: report of four cases and review of the literature
}

\author{
P Hinse, A Thie, L Lachenmayer
}

\begin{abstract}
Four cases of cervical vertebral artery (VA) dissection are reported. In three patients VA dissection was associated with neck trauma. All patients were young or middle-aged (range 27 to 49 years). In two there was a history of migraine. Pain preceded neurological symptoms from hours to six weeks. Three patients had neurological deficits including elements of the lateral medullary syndrome, and one experienced recurrent transient ischaemic attacks in the vertebrobasilar territory. Angiographic findings included irregular stenosis, occlusion and pseudoaneurysm; in two patients VA abnormalities were bilateral. All patients were treated with anticoagulants and improved. In a review of 28 cases with traumatic dissection and 29 cases with spontaneous dissection of the VA reported in the literature, distinct clinical and angiographic features emerge. Aetiology remains obscure in most cases of spontaneous dissection and management is still controversial.
\end{abstract}

Mural artery dissection is produced by penetration of blood into the vessel wall causing narrowing of the lumen and pseudoaneurysmal dilation. Thrombus may lead to complete occlusion of the arterial lumen and serve as an embolic source for distal branch occlusion. Dissection results from intimal tear or primary haemorrhage from the vasa vasorum. Although dissection of the extracranial VA is less common than dissection of the carotid artery in the neck, ${ }^{1}$ there has been an increasing number of reports on both traumatic and spontaneous VA dissection in the literature emphasising its significance as a potential cause of stroke in young and middle-aged adults.

The prevalence of VA dissection remains unknown. A substantial number of cases may go unrecognised as prodromal symptoms are not always easily interpreted and the clinical course often proves to be benign. Yet early diagnosis is essential because of important implications for treatment. To support early diagnosis we report four cases and review the literature on clinical and angiographic features of VA dissection.

\section{Case reports \\ Patient 1}

A 39 year old woman with no history of hypertension or cardio-vascular disease was involved in a motor car accident on 17 March 1989. She had suffered whiplash injuries of the neck twice previously (1978 and 1982) without complications of the nervous system.

Immediately after the accident she experienced severe, aching pain in the upper part of the right neck radiating to the ear. She was treated with a neck collar for two weeks, but pain persisted. On 28 April, six weeks after the accident, she had sudden severe vertigo and nausea. Hours later she progressively developed dysarthria, dysphagia, weakness of the right face and numbness of the left side of her body. She was admitted to our hospital the next day.

Examination revealed an alert and oriented patient with normal cardiopulmonary functions. Speech was dysarthric, and she had difficulty swallowing. Other neurological abnormalities included a right Horner's syndrome, right facial weakness, paresis of the right soft palate and minimal left hemiparesis. The deep tendon reflexes were increased in the left limbs but plantar responses were both flexor. Sensation to touch, pain and vibration was considerably diminished on the left face and limbs. CT scan showed a cerebellar infarct corresponding to the right posterior inferior cerebellar artery (PICA) distribution.

Continuous-wave (CW) Doppler detected a weak flow signal at the mastoid loop of the right VA that could not be traced intracranially by transcranial Doppler. Flow velocities in the left VA were increased suggesting compensatory flow, and the basilar artery displayed normal flow velocities.

Transfemoral digital subtraction angiography (DSA) on the day of admission revealed severe irregularities and stenosis of the third (V3) and fourth (V4) segment of the right VA. Filling of the right PICA was delayed. The left VA showed irregularities in its V4 segment without relevant narrowing of the lumen. Carotid and basilar angiograms were normal (fig 1a).

The patient was heparinised, and after 35 days anticoagulation was continued with phenprocoumon over a three month period.

The clinical course was favourable: when she was transferred for rehabilitation six weeks after admission there was still a hemi- 


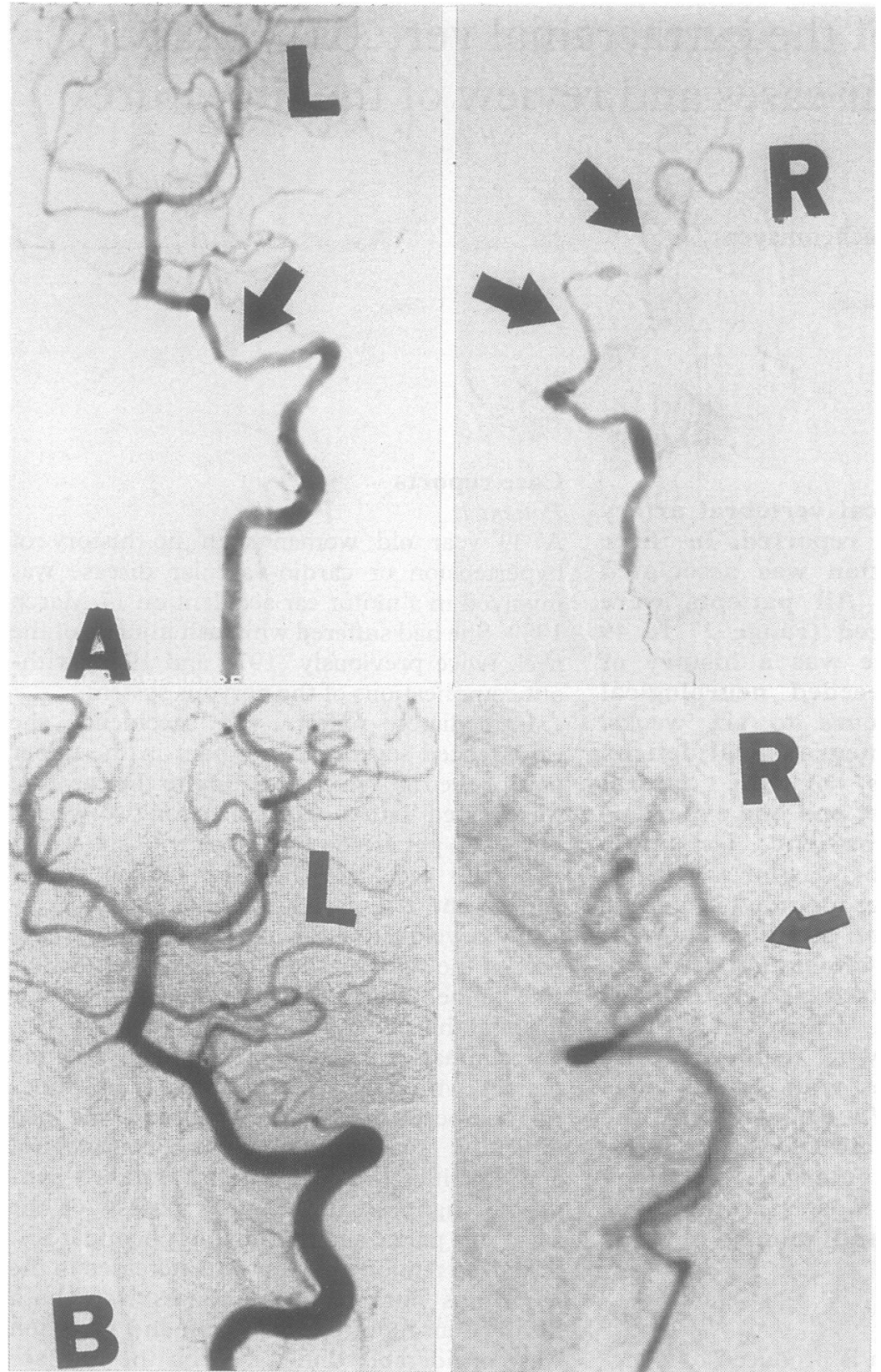

Figure 1a) Patient 1. Left and right vertebral angiograms. Severe irregularities and stenosis of $V 3$ and V4 segments of the right VA (arrows). Mild irregularities of the left $V A$ without relevant narrowing of the lumen (arrow). b) Patient 1. Follow up angiography eleven weeks later, showing occlusion of the right VA distal to the PICA (arrow). Normal left vertebral angiogram.

sensory deficit but other neurological symptoms had resolved. Follow up angiography four months after the trauma showed total occlusion of the right VA distal to the PICA. Left vertebral angiogram was normal (fig $1 \mathrm{~b}$ ).

Patient 2

A 40 year old previously healthy woman bumped into another person while skiing. Initially there was no disturbance of conciousness but she suffered a severe headache. A few hours after the accident, she suddenly developed nausea and vertigo. Her speech became slurred and she had difficulty in swallowing. She was immediately transferred to another hospital. On admission she was alert and oriented with stable vital functions. Neurological examination revealed rotatory nystagmus, increasing on right lateral gaze. Speech was dysarthric. There was diminution of touch and pain perception on the left face and the right extremities. The corneal response was impaired on the left. The gag reflex was absent and slight pharyngeal and palatal weakness was found on the left. The deep tendon reflexes were symmetrical and pyramidal tract signs were negative. There was no weakness of the extremities, but she had dysmetria of the left arm.

Angiography revealed complete occlusion of the left VA at the level of the first cervical vertebra. There was retrograde filling of the distal $1.5 \mathrm{~cm}$ of the left VA, but the left PICA could not be visualised. The right VA and BA gave a normal angiographic appearance (fig 2).

The patient was heparinised and transferred to our hospital. Follow up angiography six weeks after the accident showed complete recanalisation of the left VA. There was a small aneurysmatic dilatation at the intracranial segment. MRI visualised an infarction in the left dorsolateral medulla oblongata, correlating to the clincial findings. In addition multiple small infarcts were found in the territory of the left posterior cerebral artery and in both cerebellar hemispheres.

The patient gradually improved and she was discharged six weeks after the accident with a mild neurological deficit.

\section{Patient 3}

A 49 year old man with a history of migraine was looking up during his work at a building site and suddenly experienced an intense, sharp pain in the right side of the neck. He also noticed a numbness in the right face.

One week later after waking he noted unsteadiness of gait with a tendency to fall to the

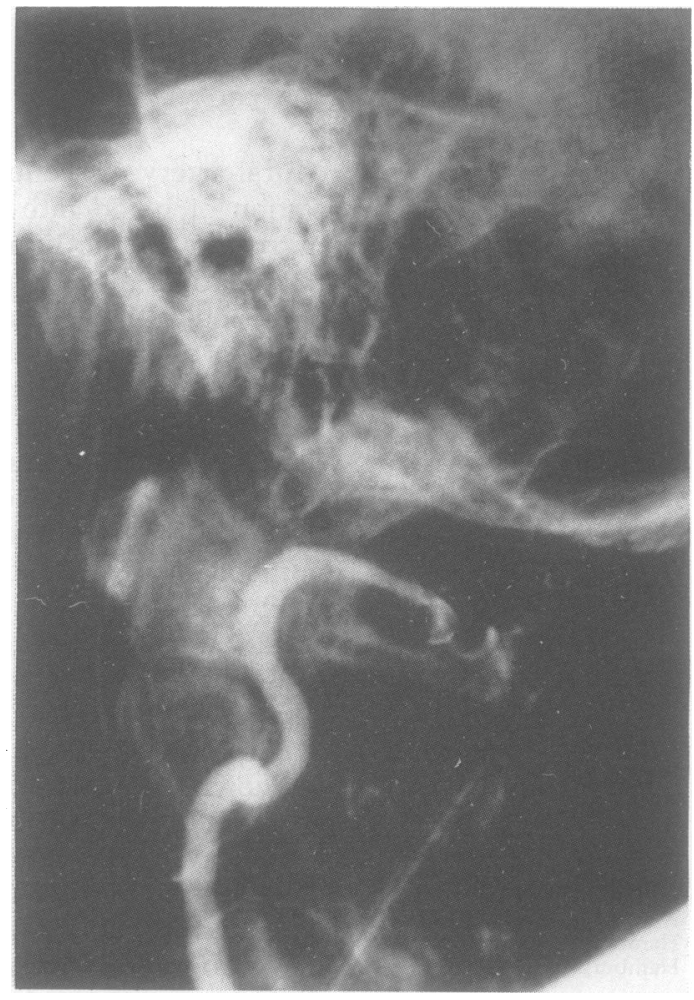

Figure 2 Patient 2. Left vertebral angiogram, lateral view. Complete occlusion of the left VA at the level of the first vertebra. 
right. Hours later he progressively developed hoarseness, nausea, vertigo, dysarthria, dysphagia and paraesthesias of the left limbs.

On admission neurological examination revealed a right Wallenberg's syndrome with crossed sensory deficit, right Horner's syndrome, right palatal paresis, weakness of the right vocal cord and mildly dysarthric speech. There was no paresis of the extremities and tendon reflexes were symmetrical.

CT scan showed marked global cerebellar atrophy. CW-Doppler suggested occlusion of the right VA. A transfemoral DSA revealed a total occlusion of the right VA at the third and fourth segments (fig 3). Only a short distal stump was filled by retrograde flow from the left VA. The right PICA could not be visualised. Left VA angiogram was normal. Anticoagulation was started with heparin.

Neurological symptoms improved rapidly, and he was discharged two weeks after admission with a mild left hemisensory deficit sparing the face. Neck pain, however, improved only slowly; on an outpatient visit two months later he still complained of right nuchal tenderness. Doppler examination six months later revealed complete recanalisation of the right VA.

\section{Patient 4}

In this 28 year old woman hypertension had been diagnosed earlier resulting in a one year treatment with a beta blocking agent. After discontinuation of therapy blood pressure remained normal. She was using oral contraceptives and had occasionally suffered from migrainous headaches.

On 13 December 1989, she experienced sudden, intense left cervical pain radiating to the left shoulder. She consulted an ortho-

Figure 3 Patient 3. Left vertebral angiogram, lateral view. Only a short distal stump of the occluded right $V A$ is filled by retrograde flow from the left $V A$ (arrow). paedic specialist who performed repeated chiropractic manipulations and prescribed a cervical collar. Pain subsided gradually after a few days, but on 23 December she experienced severe rotatory vertigo which recurred several times during subsequent days. It was combined with unsteadiness of gait, nausea and vomiting. On two occasions vertigo was initiated as she looked back over the right shoulder.

She was admitted to our hospital on 4 January 1990. There was slight unsteadiness of gait with drift to the right, but neurological examination was otherwise normal. CT scan revealed a cerebellar infarction in the left PICA territory. Neither the VAs nor the basilar artery could be detected with normal flow signals by pulsed Doppler, but this method failed to clarify the exact vascular pathology.

Transfemoral DSA showed a long irregular stenosis of the second (V2) segment of the right VA extending to the $\mathrm{Cl}$ level. (fig 4a). The left VA was occluded in its entire length with collateralisation by the ascending cervical artery which joined the left VA at the $\mathrm{Cl}$ level. The left PICA was poorly filled.

Heparin was administered for the first 21 days and substituted by coumarin. There was no recurrence of vertigo and neurological findings were normal at discharge. Doppler sonography and repeat angiography four months later revealed recanalisation of the left VA. On the right VA there were still mild calibre irregularities (fig $4 \mathrm{~b}$ ), but the lumen had normalised.

\section{Review of literature}

We reviewed 28 cases with traumatic (table 1 ) and 29 cases with spontaneous dissection (table 2) of the extracranial VA from the literature, including 15 cases reported by Chiras, ${ }^{2}$ which are not listed in table 2 . In traumatic VA dissection there were 10 males and 18 females; age ranged from seven to 60 years, with a mean age of 34 years. In spontaneous dissection there were eight males and 21 females; mean age was 40 years, ranging from 26 to 64 years.

Pain occurred in 19 patients $(68 \%)$ with traumatic and in 22 cases $(76 \%)$ with spontaneous VA dissection. In most cases (33 of 41) it was localised in the neck and occiput; diffuse, non-localised headache was noted in eight cases. Brainstem or cerebellar infarction occurred in 25 cases with traumatic VA dissection, bilateral in 10 . Of 15 cases with unilateral brainstem ischaemia, 11 showed clinical signs of Wallenberg's syndrome, implicating the dorsolateral medulla to be the main site of infarction.

Brainstem infarction occurred in 19 of 29 patients with spontaneous VA dissection, three of which were bilateral. Lateral medullary infarction was noted in 10 patients. In five patients, only transient symptoms attributable to vertebrobasilar ischaemia occurred, and three patients remained asymptomatic.

Angiography was performed in all reported cases. In traumatic dissections unilateral VA abnormalities were found in 20 patients, six 


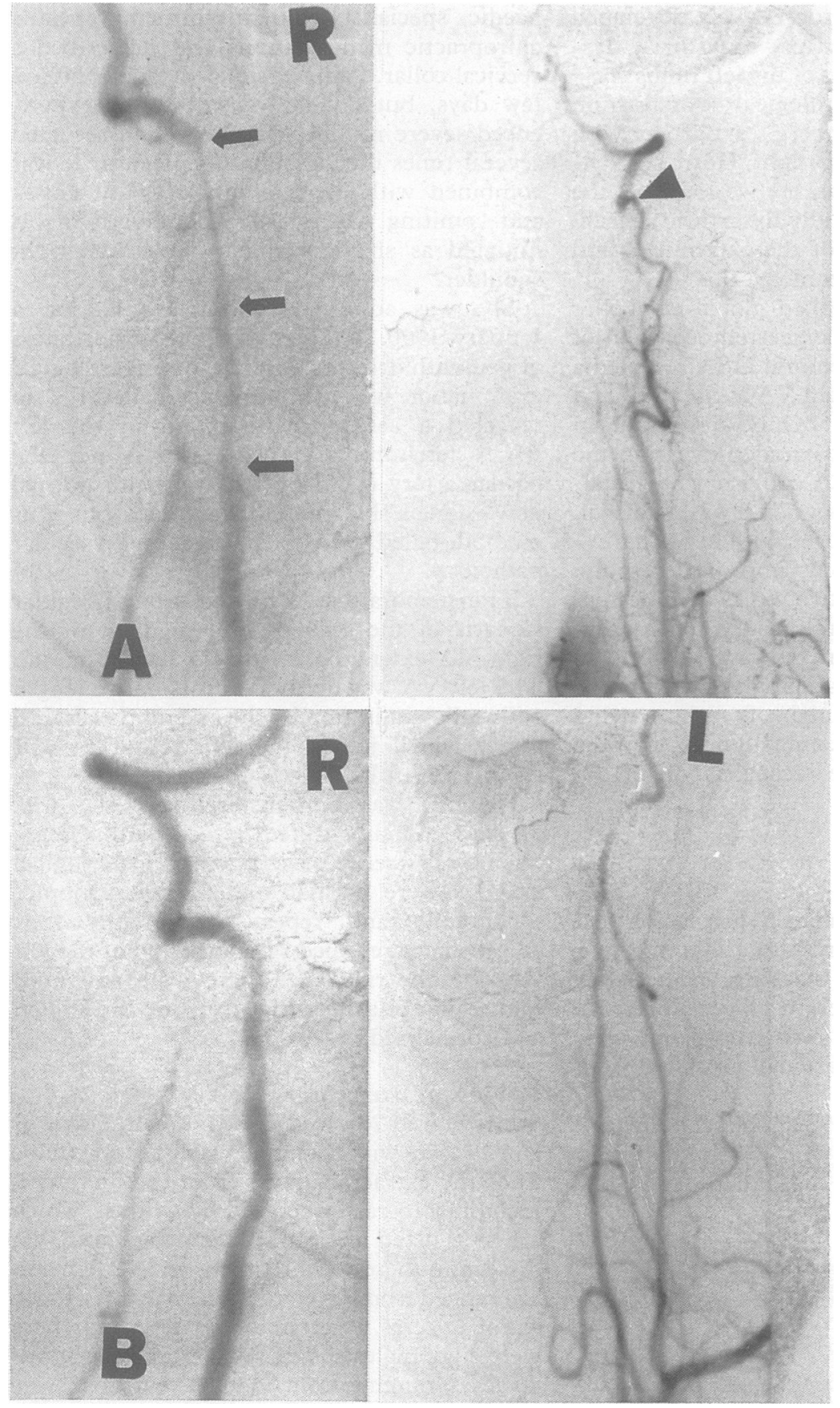

Figure 4a) Patient 4. Left and right vertebral angiograms showing a long, "stringlike" stenosis at the V2 segment of the right VA (arrows). Occlusion of the left VA with collateralisation by the ascending cervical artery which joins the left $V A$ at the $C 1$ level (arrowhead). b) Patient 4. Follow up angiography performed four months later. Recanalisation of the left $V A$, normalisation of the lumen of the right $V A$.

showed bilateral lesions, and in one patient VA angiography was normal. In four patients unilateral dissection was combined with congenital hypoplasia of the contralateral VA, bilateral VA hypoplasia was found in one patient. In 19 cases dissection was localised at the V3 segment of the VA; V2 was affected in two, V2 and V3 were involved in five patients. Stenosis of the VA was found in 17 cases, occlusion in 10 and pseudoaneurysm in four patients. In spontaneous dissection, angiography showed bilateral abnormalities in 14 cases, and 15 patients had unilateral VA involvement. Stenosis was found in 33, occlusion in seven and pseudoaneurysm in five cases. In 10 cases angiographic findings were confined to the V1 and/or V2 segment of the $\mathrm{VA}$; in 13 cases $\mathrm{V} 2$ and $\mathrm{V} 3$ were both involved, and in $\mathbf{1 6}$ cases dissection occurred at the V3 segment only. In five cases there was angiographic evidence of fibromuscular dysplasia (FMD), three of whom showed associated dissecting aneurysms of the internal carotid artery.

In spontaneous dissection the clinical course was favourable in 22 cases, in one patient severe neurological deficits persisted, and four patients died. In two cases outcome was not mentioned. In 16 cases of traumatic VA dissection there was substantial improvement of symptoms, in six cases outcome was fatal (four of which had bilateral brainstem infarction) and in two cases severe neurological deficits remained. In four cases outcome was not reported.

\section{Discussion}

Vertebral artery dissection occurs predominantly in middle-aged adults: $68 \%$ of patients with traumatic VA dissection and $80 \%$ with spontaneous dissection were aged $30-50$ years. There was a female preponderance in both groups, $64 \%$ of patients with traumatic dissection and $72 \%$ of patients with spontaneous dissection were female.

\section{Symptoms and prognosis}

Pain is a frequent, but not invariable prodromal symptom in traumatic and spontaneous VA dissection. ${ }^{21}$ In traumatic dissection it occurs immediately after the trauma (in eight of 14 reviewed cases) or delayed for hours to days (in six of 14 cases).

Pain is usually characterised as severe, dull and non-throbbing, with sudden onset, and most frequently localised in the upper part of the neck and occiput, ipsilateral to the side of dissection. It was an early symptom in all our patients. Initially consulted physicians in three of our patients $(1,3$, and 4$)$ misinterpreted the pain to be of musculoskeletal origin and physical therapy was initiated in all which failed to produce substantial relief.

Extracranial cerebral arteries are known to be pain sensitive. ${ }^{22}$ Pain in VA dissection is most likely caused by excitation of nociceptors in the vessel wall, although, the exact mechanism of pain is still not fully understood. ${ }^{23}$ Clinically, visceral pain caused by arterial dissection is frequently difficult to differentiate from pain of musculoskeletal origin, especially in cases of traumatic VA dissection in whom tenderness of neck muscles may result from trauma. Neck and posterior head-pain associated with VA dissection will therefore rarely be correctly diagnosed as long as symptoms of brainstem ischaemia are absent.

In our patients there was an interval between the onset of pain indicating the initiation of dissection, and the ischaemic event, ranging from a few hours (case 2), one week (cases 3 and 4) to six weeks (case 1). This is also a common finding in patients reported in the literature: in 11 of 25 cases $(44 \%)$ with traumatic VA dissection onset of ischaemic events was delayed with the interval ranging from a few 
Table 1 Reported cases of traumatic dissection of extracranial vertebral artery

\begin{tabular}{|c|c|c|c|c|c|c|}
\hline Reference & Age & Sex & Trauma & Clinical Syndrome & Angiography & Outcome \\
\hline $\begin{array}{l}\text { Carpenter }{ }^{13} \\
\text { Simeone }^{14} \\
\text { Lorenz }^{3} \\
\text { Mehalic }^{4} \\
\text { Davidson }\end{array}$ & $\begin{array}{l}42 \\
40 \\
39 \\
40 \\
30 \\
42\end{array}$ & $\begin{array}{l}M \\
M \\
F \\
M \\
F \\
F\end{array}$ & $\begin{array}{l}\text { Fell out of a tree } \\
\text { Car accident } \\
\text { Chiropract manipulation } \\
\text { Chiropract manipulation } \\
\text { Chiropract manipulation } \\
\text { Chiropract manipulation }\end{array}$ & $\begin{array}{l}\text { L lat medulla, spinal cord } \\
\text { Brainstem (bilateral) } \\
\text { Brainstem (bilateral) } \\
\text { R lat medulla } \\
\text { Brainstem (bilateral) } \\
\text { R pons }\end{array}$ & $\begin{array}{l}\text { LVA dissection and occlusion at C6 } \\
\text { Prox. occlusion of LVA, RVA occlusion at C2-3 } \\
\text { LVA narrowing, hypoplastic RVA, BA occlusion } \\
\text { RVA narrowing at C1-2, atherosclerotic LVA and BA } \\
\text { RVA narrowing at C1-2, hypoplastic LVA } \\
\text { Pseudoaneurysm of RVA at C2 }\end{array}$ & \multirow{5}{*}{$\begin{array}{l}\text { Died } \\
\text { Died } \\
\text { Died } \\
\text { Slight deficit } \\
\text { Severe deficit } \\
\text { Moderate } \\
\text { deficit } \\
\text { Neurolog. } \\
\text { deficit } \\
\text { Minimal } \\
\text { deficits } \\
\text { Moderate } \\
\text { deficit } \\
\text { Normal } \\
\text { Died } \\
\text { Bilateral } \\
\text { hemianopsia } \\
\text { Neurolog. } \\
\text { deficit }\end{array}$} \\
\hline Easton $^{6}$ & $\begin{array}{l}48 \\
44\end{array}$ & $\mathbf{F}$ & $\begin{array}{l}\text { Chiropract manipulation } \\
\text { Chiropract manipulation }\end{array}$ & Cerebellum & Extreme narrowing of LVA between PICA and BA & \\
\hline Parkin $^{7}$ & 23 & $\mathbf{F}$ & Chiropract manipulation & Brainstem (bilateral) & Distal LVA occlusion, hypoplastic RVA, thrombus in BA & \\
\hline $\begin{array}{l}\text { Zimmermann }^{8} \\
\text { Krueger }^{9}\end{array}$ & $\begin{array}{r}7 \\
25 \\
39\end{array}$ & $\begin{array}{l}\mathbf{M} \\
\mathbf{F}\end{array}$ & $\begin{array}{l}\text { Chiropract manipulation } \\
\text { Chiropract manipulation } \\
\text { Chiropract manipulation }\end{array}$ & $\begin{array}{l}\text { Left occipital lobe, cerebellum } \\
\text { Brainstem (bilateral) } \\
\text { Brainstem (bilateral), both } \\
\text { occipital lobes }\end{array}$ & $\begin{array}{l}\text { LVA occlusion at C2 filling defect of BA } \\
\text { (Postmortem) LVA and RVA narrowing at C1-2 } \\
\text { Severe stenosis of RVA at foram, magnum, hypoplastic LVA }\end{array}$ & \\
\hline Shermann $^{10}$ & 48 & $\mathbf{F}$ & Chiropract manipulation & Brainstem (bilateral) & Hypoplastic RVA and LVA & \\
\hline Schellhas ${ }^{11}$ & $\begin{array}{l}44 \\
35 \\
24 \\
60 \\
36 \\
31\end{array}$ & $\begin{array}{l}\mathbf{F} \\
\mathbf{M} \\
\mathbf{F} \\
\mathbf{F} \\
\mathbf{F}\end{array}$ & $\begin{array}{l}\text { Chiropract manipulation } \\
\text { Chiropract manipulation } \\
\text { Chiropract manipulation } \\
\text { Chiropract manipulation } \\
\text { Chiropract manipulation } \\
\text { Chiropract manipulation }\end{array}$ & $\begin{array}{l}\text { L lat medulla, cerebellum } \\
\text { Brainstem (bilateral) } \\
\text { Brainstem } \\
\text { Brainstem (unilateral) } \\
\text { Brainstem (bilateral) } \\
\text { L lat medulla }\end{array}$ & $\begin{array}{l}\text { Hypoplastic LVA, ending at PICA } \\
\text { LVA narrowing at } C 1-2 \text { with pseudoaneurysm } \\
\text { RVA occlusion at } C 1 \\
\text { Perforation of RVA } \\
\text { LVA dissection at } C 1 \text {, RVA dissection at } \mathrm{Cl}-2 \\
\text { LVA dissection at } \mathrm{C} \text {, focal stenosis of BA }\end{array}$ & $\begin{array}{l}\text { Mild deficit } \\
\text { Died } \\
\text { Severe deficit } \\
\text { Gradual } \\
\text { improvement }\end{array}$ \\
\hline Katirij $^{12}$ & $\begin{array}{l}32 \\
20 \\
26\end{array}$ & $\begin{array}{l}\mathbf{F} \\
\mathbf{M}\end{array}$ & $\begin{array}{l}\text { Chiropract manipulation } \\
\text { Sport accident } \\
\text { Chiropract manipulation }\end{array}$ & $\begin{array}{l}\mathrm{R} \text { lat medulla } \\
\mathrm{R} \text { lat medulla } \\
\mathrm{R} \text { lat medulla cerebellum }\end{array}$ & $\begin{array}{l}\text { RVA dissection at C1 } \\
\text { RVA occlusion at } \mathrm{C} 2 \\
\text { Dissection of RVA and LVA at } \mathrm{C} 1-6 \text {, bilateral aneurysms at } \\
\text { C5 }\end{array}$ & Mild deficit \\
\hline & $\begin{array}{l}31 \\
51\end{array}$ & $\begin{array}{l}\mathbf{F} \\
\mathbf{M}\end{array}$ & $\begin{array}{l}\text { Sport accident } \\
\text { Chiropract manipulation }\end{array}$ & $\begin{array}{l}\text { Brainstem (unilateral) } \\
\text { R lat medulla }\end{array}$ & $\begin{array}{l}\text { RVA narrowing between } \mathrm{C} 2 \text { and } \mathrm{C} 7 \\
\text { RVA occlusion at } \mathrm{C} 1-2\end{array}$ & \multirow{3}{*}{$\begin{array}{l}\text { Normal } \\
\text { Steady } \\
\text { improvement } \\
\text { Died } \\
\text { Gradual } \\
\text { improvement } \\
\text { Mild deficit } \\
\text { Normal }\end{array}$} \\
\hline Present report & $\begin{array}{l}34 \\
39\end{array}$ & $\begin{array}{l}\mathbf{M} \\
\mathbf{F}\end{array}$ & $\begin{array}{l}\text { Sport accident } \\
\text { Car accident }\end{array}$ & $\begin{array}{l}\text { Brainstem (bilateral) } \\
\mathrm{R} \text { lat medulla }\end{array}$ & $\begin{array}{l}\text { Irregularity of LVA, BA and both PCAs } \\
\text { Severe RVA stenosis at C1-2, LVA irregularities at the } \\
\text { intracranial segment }\end{array}$ & \\
\hline & $\begin{array}{l}40 \\
28\end{array}$ & $\begin{array}{l}\mathrm{F} \\
\mathrm{F}\end{array}$ & $\begin{array}{l}\text { Sport accident } \\
\text { Chiropract manipulation }\end{array}$ & $\begin{array}{l}\text { L lat medulla } \\
\text { Recurrent vertebrobasilar TIA }\end{array}$ & $\begin{array}{l}\text { LVA occlusion at C2 } \\
\text { Irregular RVA stenosis from C2-C6, LVA occlusion }\end{array}$ & \\
\hline
\end{tabular}

LVA = left vertebral artery; RVA = right vertebral artery; BA = basilar artery; PICA = posterior inferior cerebellar artery; ICA = internal carotid artery;

$\mathrm{PCA}=$ posterior cerebral artery.

hours to four days. A six week interval found in one of our patients is remarkable in that presumed thrombosis and embolism apparently did not occur until six weeks after the probable moment of arterial injury.

It exemplifies the importance of a careful search for recent trauma in patients with VA dissection. In this patient, post-traumatic stiffness of cervical muscles had mostly resolved during these six weeks, but severe unilateral neck pain persisted which can retrospectively be interpreted as a clue to the diagnosis of arterial dissection. In 28 of 39 patients with focal cerebral ischaemia symptoms initially evolved suddenly (19 cases) or progressively ( 9 cases). In 11 patients symptoms initially fluctuated, reflecting recurring cerebral ischaemia during a two to four week period after onset. Three of our patients (cases 1, 2,3) showed clinical and radiological evidence of lateral medullary infarction. Wallenberg's syndrome was found in $50 \%$ of patients with brainstem infarction associated with VA dissection reported in the literature. The clinical course was favourable in all our patients: there was no recurrence of ischaemic events during follow up (three to six months) and symptoms improved considerably in all.

Substantial improvement of symptoms commonly occurs in surviving patients with VA dissection, probably due to young age and the lack of artherosclerotic disease in most: it was observed in $75 \%$ of patients with spontaneous dissection and in $52 \%$ of patients with

Table 2 Reported cases of spontaneous dissection of extracranial vertebral artery

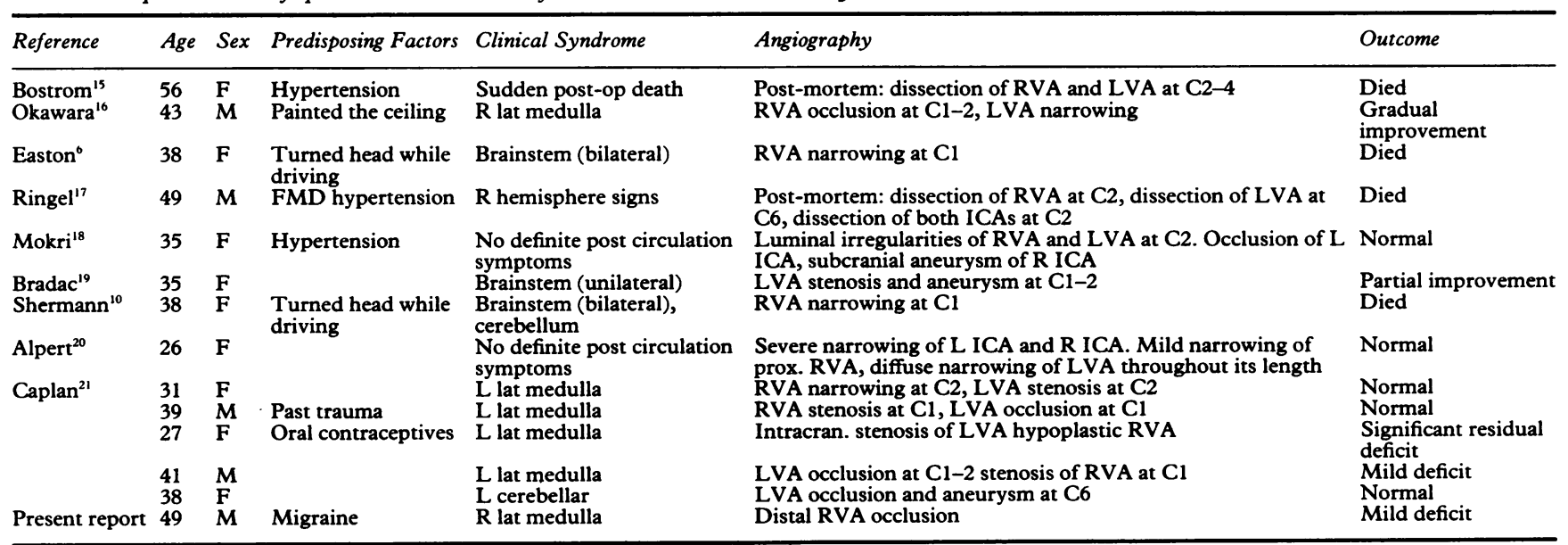


traumatic VA dissection. Long term follow up did not reveal recurrence of cerebral ischaemia in any of the reported cases.

On the other hand, fatal outcome is not rare: it was seen in six of $28(21 \%)$ cases of traumatic and in four of $29(14 \%)$ cases of spontaneous dissection.

\section{Angiography}

Diagnosis is essentially based upon angiography. Characteristic angiographic findings in both traumatic and non traumatic VA dissection include: 1) long irregular, luminal stenosis; 2) occlusion of the artery; 3 ) pseudoaneurysm, and 4) "double lumen". ${ }^{25}$ Stenosis is by far the most common finding in both traumatic $(54 \%)$ and spontaneous dissection (78\%). It is caused by subintimal haematoma. Frequently dissection extends circumferentially around the lumen over a long segment, giving rise to a characteristic "string-like" appearence. ${ }^{25}$ Luminal surface irregularities may be due to intimal folding. Narrowing of the lumen often proves to be severe and complete occlusion may ensue.

In our patients angiography revealed severe stenosis in two cases ( 1 and 4) and occlusion in three (2, 3 and 4). Pathological findings were located at the V3 segment in all patients, in one patient (case 4) dissection also involved the V2 segment. The V3 segment is most frequently affected in both traumatic and non-traumatic dissection, but there is significant higher incidence of $\mathrm{V} 1 / \mathrm{V} 2$ involvement in spontaneous dissection ( $54 \%$ of the reported cases).

There is a high incidence of bilateral VA involvement in spontaneous dissection $50 \%$ of the reported cases) suggesting a predisposing arteriopathy, the nature of which remains obscure in most cases.

\section{Doppler ultrasound}

To our knowledge, the role of Doppler ultrasound in VA dissection has not been studied systematically. In dissection of the internal carotid artery high-resistance Doppler flow patterns in arteries proximal to the lesion have been described. ${ }^{26} 27$ Findings included reduced flow velocities, alternating flow direction, and high-amplitude Doppler signals.

In our patients, Doppler ultrasound during the acute phase correctly detected VA occlusion in two patients (cases 3, 4). It failed to identify the exact lesion type in two arteries (cases 1,4 ), but showed some abnormality that encouraged angiographic examination. Follow up findings (cases 3, 4) disclosed recanalisation of previously occluded vessels.

\section{Aetiology}

In traumatic VA dissection, mechanical stretching and compression of the artery may cause intimal tearing and consecutive intramural haematoma. Most reported cases have been associated with chiropractical neck manipulation, ${ }^{3-12}$ commonly consisting of abrupt and forceful rotational head movement, with or without hyperextension of the head.

The VA is most susceptible to mechanical injury at its mobile distal part after leaving the transverse foramen of the axis and before entering the intracranial cavity. The anatomical relationship between the VA and its neighbouring bony structures and ligaments, and the special mechanisms of head and neck movement may account for the unique vulnerability to mechanical injury at the atlanto-axial level. ${ }^{4-11} 162829$ A reduction of vertebral blood flow during rotational and hyperextensive head movements has been demonstrated angiographically. ${ }^{30-35}$

In most cases of spontaneous VA dissection aetiology remains obscure. The disorder mostly affects younger and otherwise healthy adults. Of particular interest is the relationship between minor neck trauma often resulting from ordinary head movement and VA dissection. In one of our cases (3), dissection occurred with pronounced retroflexion of the head while looking up. Other reports ${ }^{61036}$ have stressed the temporal coincidence of trivial neck trauma and the onset of VA dissection. In these cases there is a striking discrepancy between the relatively minor force of injury and the severity of vascular lesion suggesting enhanced arterial vulnerability. Various predisposing conditions have been discussed including FMD, hypertension, migraine, and then use of oral contraceptives. $^{215172137}$ Of 29 cases reported in the literature such factors were noted in 17: hypertension (10 cases), FMD (six cases), oral contraceptives (five cases) and migraine (four cases). FMD has long been recognised as a predisposing factor for arterial dissection, ${ }^{217}$ but the significance of hypertension, migraine and oral contraceptive use in the pathogenesis of VA dissection is still obscure. In 28 cases of traumatic VA dissection only three patients had a history of hypertension with no preexisting cardiovascular disease in the rest. Post mortem examination performed in five fatal cases revealed no evidence of vascular mural changes suggesting degenerative or inflammatory arteriopathy. ${ }^{31012-14}$

\section{Therapy}

There is no general agreement on the best management of VA dissection. Initial treatment with anticoagulants has been recommended $^{11} 123536$ to prevent progressive thrombosis and thromboembolism. All of our patients were heparinised after diagnosis was established. Duration of heparinisation ranged from five days (patient 3 ) to 35 days (patient 1). Anticoagulation with coumadin was continued in two, the other patients received antiplatelet agents after initial heparinisation. We did not observe any complications of anticoagulant therapy and there was no recurrence of ischaemic symptoms during follow up (range three to six months). Repeat angiography or Doppler sonography after four months revealed recanalisation of the previously occluded VA in patients 3 and 4 and occlusion of the previously stenosed VA in patient 1 .

Cerebral ischaemic symptoms may occur as a consequence of haemodynamic failure, or by thromboembolism with obstruction of distal vessels. Embolism can be postulated when stenosis is haemodynamically insignificant and/ 
or when there is arteriographic evidence of distal embolus. ${ }^{38}{ }^{39}$ In the case of embolism initial anticoagulant therapy seems to be reasonable. If dissection includes the intracranial VA segment, subarachnoid haemorrhage should be excluded before anticoagulants are administered. If the use of anticoagulants is contraindicated, patients might benefit from antiplatelet drugs.

We prefer to perform repeat angiography three months after initiation of anticoagulant therapy to decide on further therapy. Anticoagulants are discontinued if spontaneous recanalisation occurred, and the arterial lumen appears smooth. If the vessel remains occluded, we prefer to continue anticoagulants for six months followed by antiplatelet drugs for two years. In the case of persisting pseudoaneurysm, we use the same regime, but further study on the natural history of these lesions is urgently needed.

1 Culebras A, Hodge CJ, Petro GR. Carotid and vertebral dissecting hematomas. In JF Toole, ed. Handbook of Clinical Neurology, Vol 10 (54). Vascular diseases Part II. Amsterdam: Elsevier, 1989.

2 Chiras J, Marciano S, Molina JV, Toubul J, Poirier B, Bories J. Spontaneous dissecting aneurysm of the extracranial J. Spontaneous dissecting aneurysm of the extracranial
vertebral artery (20 cases). Neuroradiology 1985;27: vertebra

3 Lorenz R, Vogelsang HG. Thrombose der Arteria basilaris nach chiropraktischen Manipulationen an der Halswirbelsäule. Dtsch med Wschr 1972;97:36-43.

4 Mehalic T, Farhat SM. Vertebral artery injury from chiropractic manipulation of the neck. Surg Neurol 1974;2 125-9.

5 Davidson KC, Weiford EC, Dixon GD. Traumatic vertebral artery pseudoaneurysm following chiropractic manipulation. Radiology 1975;115:651-2.

6 Easton JD, Sherman DG. Cervical manipulation and stroke. Stroke 1977;8:594-7.

7 Parkin PJ, Wallis WE, Wilson JL. Vertebral artery occlusion following manipulation of the neck. $N Z$ Med $J 1978$; 88:441-3.

8 Zimmermann AW, Kumar AJ, Gadoth N, Hodges FJ, Traumatic vertebrobasilar occlusive disease in childhood. Traumatic vertebrobasilar occlusive dise
Neurology (Minneap) 1978;28:185-8.

9 Krueger BR, Okazaki H. Vertebral-basilar distribution infarction following chiropractic cervical manipulation. Mayo Clin Proc 1980;55:322-32.

10 Sherman DG, Hart RG, Easton JD. Abrupt change in head position and cerebral infarction. Stroke 1981;12:2-6.

11 Schellhas KP, Latchaw RE, Wending LR, et al. Verterobasilar injuries following cervical manipulation. JAMA 1980;244:1450-3.

12 Katirji MB, Reinmuth OM, Latchaw RE. Stroke due to vertebral artery injury. Arch Neurol 1985;42:242-8.

13 Carpenter S. Injury of neck as cause of vertebral artery thrombosis. J Neurosurg 1961;18:849-53.

14 Simeone FA, Goldberg HI. Thrombosis of the vertebral artery from hyperextension injury of the neck. J Neurosurg 1968;29:540-4.
15 Boström K, Liliequist B. Primary dissecting aneurysm of the extracranial part of the internal carotid and vertebral arteries. Neurology 1967;17:179-86.

16 Okawara S, Nibbelink D. Vertebral artery occlusion following hyperextension and rotation of the head. Stroke 1974;5:640-2.

17 Ringel S, Harrison S, Norenberg M, Austin J. Fibromuscular dysplasia: multiple "spontaneous" dissecting aneurysms of the major cervical arteries. Ann Neurol 1977;1:301-4.

18 Mokri $B$, Housero $W$, Sundt TM. Idiopathic regressing arteriopathy. Ann Neurol 1977;2:466-72.

19 Bradac GB, Kaernbach A, Bolk-Weischedel D, Finck GA. Spontaneous dissecting aneurysm of cervical cerebral arteries. Neuroradiology 1981;21:149-54.

20 Alpert J, Gerson L, Hall R, Hallmann G. Reversible angiopathy. Stroke 1982;13:100, 105

21 Caplan LR, Zarins CK, Hemmati M. Spontaneous dissection of the extracranial vertebral arteries. Stroke 1985;16:1030-8.

22 Norregaard TV, Moskowitz MA. Substance $P$ and the sensory innervation of intracranial and extracranial feline sensory innervation of intracranial and ex

23 Tatemichi TK Mohr JP Migraine and stroke. In: Barnett HJ, Stein BM, Mohr JP, Yatsu FM, eds. Stroke: pathophysiology, diagnosis and management, Vol 2. New York: Churchill Livingstone, 1986:860.

24 Caplan LR, Stein RW. Stroke. A clinical approach. Butterworths: Boston, 1986

25 Goldberg HI. Cerebral Angiography. In: Barnett HJ, Stein BM, Mohr JP, Yatsu FM, eds. Stroke: pathophysiology, diagnosis and management, Vol 1. New York: Churchill Livingstone, 1986:232-5.

26 Hennerici $M$, Steinke $W$, Rautenberg $W$. High resistance flow pattern in extracranial carotid dissection. Arch Neurol 1989;46:670-2.

27 Eljamel MSM, Humphrey PRD, Shaw MDM. Dissection of the cervical internal carotid artery. The role of Doppler/ Duplex studies and conservative management. J Neurol Deurosurg Psychiatry 1990;53:379-83.

28 Schneider RC, Gosch HH, Taren JA, et al. Blood vessel trauma following head and neck injuries. Clin Neurosurg 1972;19:312-54.

29 Tatlow WFT, Banner HG. Syndrome of vertebral artery compression. Neurology 1957;7:331-40.

30 Faris AA, Poser CM, Wilmore DW, Agnew CH. Radiologic visualization of neck vessels in healthy men. Neurology (Minneap) 1963;13:386-96.

31 Brown BSJ, Tissington-Tatlow WF. Radiographic studies of the vertebral arteries in cadavers. Effects of position and traction on the head. Radiology 1963;81:80-8.

32 Barton JW, Margolis MT. Rotational obstruction of the vertebral artery at the atlantoaxial joint. Neuroradiology 1975;9:117-20.

33 Husni EA, Bell HS, Storer J. Mechanical occlusion of the vertebral artery: a new clinical concept. JAMA 1966;196:475-8.

34 de Kleyn A, Nieuwenhuyse P. Schwindelanfalle und Nystagmus bei einer bestimmten Stellung des Kopfes. Acta oto-laryng 1927:11:155.

35 Sheehan S, Bauer RB, Meyer JS. Vertebral artery compression in cervical spondylosis: Arteriographic demonstration during life of vertebral artery insufficiency due to rotation and extension of the neck. Neurology 1960;10:968-86

36 Hart RG, Easton JD. Dissections. Stroke 1985;16:925-7.

37 Alexander CB, Burger PC, Goree JA. Dissecting aneurysm of the basilar artery in 2 patients. Stroke 1979;10:294-9.

38 Hart RG, Easton JD. Dissections and trauma of cervicocerebral arteries. In: Barnett HJ, Stein BM, Mohr JP, Yatsu FM, eds. Stroke: pathophysiology, Vol 2. Diagnosis and management. New York: Churchill Livingstone, 1986:775-88.

39 Hart RG. Vertebral artery dissection. Neurology 1988; 38:987-9. 